\title{
AC 2008-616: IMPACT OF INSTRUCTORS' USE OF THE TABLET PC ON STUDENT LEARNING AND CLASSROOM ATTENDANCE
}

\author{
Kyu Yon Lim, Pennsylvania State University \\ Kyu Yon Lim is a PhD candidate majoring in Instructional Systems with emphasis of \\ instructional design with emerging technology. Her research interests relate to technology \\ integration, generative learning, and problem-based learning. She can be contacted at \\ kylim@psu.edu.
}

\section{Roxanne Toto, Pennsylvania State University, University Park}

Dr. Roxanne Toto is an Instructional Designer and e-Learning Support Specialist for the Leonhard Center for the Enhancement of Engineering Education at the Pennsylvania State University where she teaches faculty, teaching assistants, and staff to integrate technology into the teaching and learning process. Her research interests include how learning occurs, instructional design for emerging technologies, and the assessment of learning in technological environments. Dr. Toto holds an M.S. degree from Philadelphia University in Instructional Design and Technology as well as a Ph.D. from the Pennsylvania State University in Instructional Systems. She can be contacted at rtoto@psu.edu.

\section{Hien Nguyen, Pennsylvania State University}

Hien Nguyen is a doctoral student in Instructional Systems at Penn State University. She is also a research assistant at the Leonhard Center for the Enhancement of Engineering Education and at the College of Information Sciences and Technology at Penn State. Her research interests include the use of digital ink technologies in education, problem based learning, group cognition, learning communities, and cross-cultural collaborative learning. Hien can be reached at htn126@psu.edu.

\section{Sarah Zappe, Pennsylvania State University}

Sarah E. Zappe is Research Associate and Director of Assessment and Instructional Support for the Leonhard Center for the Enhancement of Engineering Education at Pennsylvania State University. Her expertise and research interests relate to the use of think-aloud methodologies to elicit cognitive processes and strategies in assessment and related tasks. In her position, Dr. Zappe is responsible for supporting curricular assessment and developing instructional support programs for faculty and teaching assistants in the College of Engineering. She can be contacted at ser163@psu.edu.

\section{Thomas Litzinger, Pennsylvania State University}

Tom Litzinger is currently Director of the Leonhard Center for the Enhancement of Engineering Education and a Professor of Mechanical Engineering at Penn State, where he has been on the faculty since 1985. His work in engineering education involves curricular reform, teaching and learning innovations, faculty development, and assessment. He teaches and conducts research in the areas of combustion and thermal sciences. He can be contacted at tal2@psu.edu.

\section{Mark Wharton, Pennsylvania State University}

Mark J. Wharton is an Assistant Professor of Electrical Engineering at Penn State. He teaches undergraduate courses in Electronics Electronics I, II, and III) and Senior Project Design, the EE capstone design course. He received his B.S. in Electrical Engineering from Penn State and his M.S. from the University of Colorado in Boulder. Prior to working at Penn State, Mark spent over 30 years in industry as an Electronic Design Engineer. He can be contacted by phone at 814-865-2091 or by email at MarkWharton@psu.edu. 
John M. Cimbala received his BS degree in Aerospace Engineering in 1979 from The Pennsylvania State University. From there he went to The California Institute of Technology where he obtained his MS degree in 1980 and his Ph.D. degree in 1984 in Aeronautics under the direction of Professor Anatol Roshko. In July of 1984, Dr. Cimbala returned to Penn State as Assistant Professor of Mechanical Engineering. In July of 1990, he was promoted to Associate Professor of Mechanical Engineering, and in July of 1997, he was promoted to Professor of Mechanical Engineering. During the academic year 1993-94, Professor Cimbala took a sabbatical leave from the University, and worked at NASA Langley Research Center, where he advanced his knowledge of computational fluid dynamics (CFD) and turbulence modeling. During the academic year 2002-03, Professor Cimbala took a sabbatical leave from the University to write an undergraduate fluid mechanics textbook, "Fluid Mechanics: Fundamentals and Applications", Y. A. Çengel and J. M. Cimbala, McGraw-Hill, New York, 2006. Professor Cimbala teaches and does research in fluid mechanics, thermodynamics, heat transfer, instrumentation, and indoor air quality, and he also enjoys studying new ways of teaching, especially with technology. John can be contacted atjmc6@psu.edu. 


\title{
Impact of Instructors' Use of the Tablet PC on Student Learning and Classroom Attendance
}

\begin{abstract}
This paper reports on a study examining the effects of posting annotated instructor notes generated with Tablet PCs in two 300-level engineering classrooms at a large land-grant university in the United States. The purpose of this study is to explore the impact of sharing instructor notes on students' attendance, note-taking behaviors, and learning. In Course A, the instructor posted detailed pre-notes in lieu of a textbook at the beginning of the semester and then posted annotated notes immediately after each class. In Course B, the instructor posted rough outline notes as pre-notes before each class, but posted the annotated notes under two three-week long alternating time conditions. In the first condition the instructor did not post the annotated notes until several days prior to assessment. In the second condition the instructor posted annotated notes after class. The authors applied both qualitative and quantitative methods to investigate the research questions. The research findings reveal that classroom attendance decreased gradually in both courses as the semester progressed, regardless of the difference in note-posting strategy. The results also indicate that student perceptions of annotated note posting vary widely. On one hand, students see annotated notes as a learning aid for studying and selfchecking, while others see annotated notes as a reason to not come to class. Practical implications and future research are described.
\end{abstract}

\section{Background}

The advantages of Tablet PC as an instructional tool are numerous. The Tablet PC has the potential to combine the advantages of traditional presentation methods such as chalkboards, overhead projectors and PowerPoint presentations while mitigating their limitations[1]. The Tablet PC has several educational applications including; the ability to support active learning in the classroom, as a lecture aid in classroom, and as a student-centered learning tool[2]. Tablet PCs embody a technology that affords for the capture and recording of natural handwriting as "digital ink." Digital ink in many ways presents a natural extension of thought processes, allowing us to write as we think in a documented spontaneous natural form. Digital ink provides an electronic capture of writing, drawing, collaboration, and annotating. Digital ink enables instructors to prepare, actively teach, and accurately document classroom activities which can be used for later retrieval, dissemination, and review. These captured digital notes are a distinct advantage of incorporating Tablet PCs into the classroom. Writing digitally permits the instructor to prepare a line of thought for a lecture while affording the opportunity for interaction, construction, and spontaneity during class. But the ability to capture an iterative process that includes the instructor's original systematic structured content while incorporating instructor and student comments and interactions has the potential to strengthen the teaching and learning process.

In 2005, the College of Engineering at a large land-grant university launched an initiative to provide teaching faculty with Tablet PCs to use in the classroom. Since its inception, 
approximately $17 \%$ of teaching faculty in engineering have adopted a Tablet PC for use in the classroom. As part of the initiative, the faculty members received support, in the form of individual work sessions and informal group lunches where various technological and pedagogical issues were discussed.

Through these work sessions and lunches, an emerging theme and repeated concern was voiced by faculty using Tablet PCs. Specifically, faculty members became increasingly interested in the benefits and consequences of posting annotated digital notes for student access. In response to this concern, two lunch sessions were held with the purpose of discussing both the advantages and disadvantages of posting versus not posting annotated classroom notes for students.

Overall, faculty presented a diverse range of opinions based on their teaching experience, with the key question being whether or not instructor notes should be made available to students. Faculty who were proponents of posting notes stated that sharing and posting notes "was a natural consequence" of using the tablet. Benefits of posting class notes included the accommodation of various learning styles and the ability of students to verify and self-check their own learning using the instructor notes. Additionally, annotated notes provide for more authentic learning as these collaboratively built annotations reflect meaningfully constructed relationships among the course concepts. Faculty who were against posting notes voiced concerns which included: decreased student attention and class attendance, the ability to take good notes, and potentially diminished student learning.

Traditionally, providing instructor notes as an instructional strategy has been shown to promote learning [3-5]. Kiewra found that student notes tended to be incomplete and often inadequate for review. Additionally he suggests that instructors can facilitate student learning by providing partial notes prior to lectures. Barnett's 2003 study [6] supported this use of partial notes (with fill-in-the-blank spaces), as students who utilized this strategy performed better than students who had the full instructor-provided notes. However, Barnett's study also supported the idea that students who took their own individual notes also performed better than students with their full instructor notes. This study supports some faculty members' concerns that perhaps providing full notes discourages students from taking responsibility for their learning on two points. If students rely on faculty notes and no longer take their own notes, then 1) they stand to lose the advantage that the act of note-taking provides for learning and 2) they stand to lose the ability to develop good note-taking strategies. Bonner and Holiday [7] suggested that many college students have inadequate note-taking strategies and weak self-regulating strategies. They offer prompting students on how to take notes during class. Providing full instructor notes then to students may further add to an already existing problem.

Other studies have provided support and suggestions for how lecture notes could potentially increase student learning. For example, Grabe and Christopherson [4] studied the relationship among students' use of lecture resources, class attendance, and examination achievement. They found that there are significant positive correlations between students' use of lecture resources and achievement. The study also provided some evidence that students may have relied on online lecture resources when they were not in class in order to do well in exams. While this study did not involve the use of Tablet PCs in creating and generating instructor notes, it does offer some insight into some of the potential benefits that providing the notes might have. 
Based on the interest faculty had concerning the pros and cons of posting notes and the concerns voiced at the lunch, we decided to explore the impact of posting and not posting notes on students' behavior and perceptions of learning. The purpose of this paper is to investigate the phenomenon of the impact of sharing instructor notes on students' attendance, note-taking behaviors, and learning in a classroom environment. Specifically, the following research questions are explored:

1. How does the timing of posting, (e.g., before or after class) and the completeness of those notes affect student attendance?

2. What are the students' perceptions of their own classroom attendance, note-taking behavior, and learning when instructors' notes are posted either before and/or after class?

3. What are the relationships (if any) among students' classroom attendance, note-taking behaviors, and achievement scores?

In order to explore these questions, an initial study was conducted in two engineering courses. Data collected from students included attendance, note-taking behavior, and measures of learning. In addition the two instructors were interviewed to understand their motivation and approaches to posting notes. The results of this paper may provide some practical insights and implications for those instructors who are using the Tablet PC in the classroom and who wonder whether or not they should make these notes available to their students.

\section{Context of the study}

\section{Description of Courses}

Two 300-level engineering courses were investigated in this study. The courses were taught by different instructors in different disciplines in engineering. Course A is a four-credit required course for junior level mechanical engineering majors; Course B is a four-credit required course for junior level electrical and computer science engineering majors. Both courses met for three lecture periods and one lab session each week.

Instructors of both courses used Tablet PCs throughout the semester in order to present information and make annotations on-the-fly in class. Also, both instructors shared their lecture notes with their students via a course management system to support and reinforce student learning. However, the instructors adopted different note-posting strategies, based on the course objectives and their personal teaching philosophy.

In Course A, the instructor posted detailed pre-notes at the beginning of the semester. These prenotes were used in lieu of a textbook. During class, the instructor went through these notes briefly, and then spent most of the class time working out example problems by writing on the Tablet PC and providing material and examples not in the posted notes. After class, the instructor for Course A posted the annotated-notes typically within an hour of the lecture.

In Course B, the instructor posted rough outline notes as pre-notes, consisting mostly of topical headings and figures on the day before each lecture class. Students were asked to print out a copy of the pre-notes and bring them to class so that they could work along with the instructor. 
Annotated instructor notes were not always provided to the students immediately following class. Rather, for purposes of this study, the instructor alternated his posting strategy every three weeks. During two 3-week periods of time, he posted annotated lecture notes immediately following class. For the other periods of time, he only posted the annotated notes several days prior to the section exam. This cycle was repeated twice over the course of the semester. Most students were unaware that this was being done. Under both conditions students had a complete set of notes available to them to study for exams.

\section{Instructor perceptions of posting notes}

The instructor of each class was asked to describe their perceptions regarding the posting of notes in their course. Specifically, the instructors were asked to describe the perceived benefits, the perceived impact on student note-taking behavior, and the perceived impact on student attendance.

The instructor for Course A described having "mixed feelings" regarding posting notes. However, he did note a great benefit of posting the notes: "The advantage is that students can pay more attention to what is going on in class rather than frantically taking notes. I can cover more material as well, knowing that the students don't have to 'keep up' with me." He later noted that while note-taking can be beneficial to students, "Taking too many notes is counterproductive, however, since [students] can't concentrate on what is being discussed. So, my opinion is that students should jot down a few of the very important items discussed during the lecture, but leave the details to the posted notes that they can download later." The instructor for Course B also described similar benefits when providing the notes to the students. Specifically, he noted that providing the notes "saves me the time that would be required for sketching figures and diagrams." He expands on this thought by stating,

The process of taking notes in class is helpful to the majority of students.

However, there is a balance to be obtained. If a student is so preoccupied being a stenographer then they will not have enough time to absorb new concepts or ask questions. So providing notes to the students in rough outline form with figures, diagrams, and problem statements, will relieve some of the stenographic burden.

While both instructors acknowledged positive impacts of using the Tablet PC and posting notes, both also discussed potential disadvantages of providing notes to the students. For example, the instructor for Course A stated, that "The disadvantages are that students find class more boring when they don't have to take notes. Some of them fall asleep. Many students skip class altogether, knowing that they can simply download the notes at a later time." He continued this line of thought with the following statement:

Attendance has definitely gone down since I started using the Tablet PC and posting notes on the website. I have mixed feelings about this. I think the students learn more when they come to class, and I feel a bit frustrated when I see less than half the students in attendance. On the other hand, the students who choose to skip class apparently feel that they can learn enough from the posted notes to get the grade they want in the class - I don't agree, but they should have that choice, even if it is not a wise one. 
The instructor for Course B also perceived a decrease in attendance:

I think that I can see a correlation between attendance and the posting of annotated notes. During semesters when I have posted annotated notes immediately after class, attendance seemed to decline. Many students would say (in surveys conducted during the semester) that they felt no need to attend class if the notes were made available to them; they could simply study on their own. During semesters when I was not posting annotated notes I felt that attendance was better.

This instructor also suggested that this attendance issue might be influenced by certain characteristics of the course, such as whether it was required or an elective, and by student characteristics, such as level of interest in the material and potentially the major.

These two courses formed the basis for the exploratory investigation of student attendance, notetaking behavior and perceptions of learning.

\section{Methodology}

Classroom attendance in both courses was measured based on student self-report and direct observation. Three separate measures were used. First, each Monday from the third week to the fifteenth week of the semester, participants were asked to report their attendance for each class session during the previous week. Second, the researchers counted the number of students who were physically present in the class each Monday to check the students' self-report. Third, at the end of the semester, students were also asked in a survey how frequently they had missed class throughout the semester.

Students' achievement was based on the final course grade, which is based on the average of exam scores and homework assignments. Both instructors administered biweekly homework assignments and three exams.

Students' perceptions of their attendance, note-taking behavior and learning related to the instructor's note posting strategy were measured by a questionnaire developed by the researchers. Both Likert-type questions and open-ended questions were included in the survey. Table1 displays the demographic information for the students who completed the survey. Table 2 displays the closed items from the survey.

The majority of the participants who responded to the survey were males. Approximately $78 \%$ of the respondents for Course A were male; $92 \%$ in Course B were male. Although these classes are intended to be taken in the junior year a substantial portion $(\sim 30 \%)$ of the students enrolled reported being seniors. This may be because they had participated in a co-op experience or were potentially behind in their academic studies. 
Table 1. Demographics of participants

\begin{tabular}{l|l|c|c}
\hline \multirow{2}{*}{\multicolumn{2}{c|}{ Categories }} & \multicolumn{2}{c}{ Number of participants (\%) } \\
\cline { 3 - 4 } \multicolumn{2}{c|}{} & $\begin{array}{c}\text { Course A } \\
(\mathbf{n = 4 6 )}\end{array}$ & $\begin{array}{c}\text { Course B } \\
(\mathbf{n = 4 0 )}\end{array}$ \\
\hline Gender & Male & $36(78.26 \%)$ & $37(92.50 \%)$ \\
& Female & $10(21.74 \%)$ & $3(7.50 \%)$ \\
\hline Grade level & Senior & $13(28.26 \%)$ & $12(30.00 \%)$ \\
& Junior & $33(71.74 \%)$ & $27(67.50 \%)$ \\
& Graduate level & - & $1(2.50 \%)$ \\
\hline Major & Electrical Engineering & - & $31(77.50 \%)$ \\
& Mechanical Engineering & $46(100 \%)$ & - \\
& Computer Science & - & $8(20.00 \%)$ \\
& Physics & - & $1(2.50 \%)$ \\
\hline Expected & A & $21(45.65 \%)$ & $5(12.5 \%)$ \\
Grade & B & $22(47.83 \%)$ & $20(50.00 \%)$ \\
& C & $3(6.52 \%)$ & $14(35.00 \%)$ \\
& D & - & $1(2.50 \%)$ \\
& F & - & - \\
\hline
\end{tabular}

\section{Data analysis}

A mixed methods approach, using qualitative and quantitative methods, was used to analyze the data collected in the study. To address research question 1, the frequency of attendance for each lecture was analyzed. To answer research question 2 , survey data collected from the participants were analyzed using descriptive statistics. In addition, qualitative data from open-ended items were explored using content analysis to further explain the results of the descriptive statistics. Finally, to explore research question 3 , researchers conducted correlational analyses to examine the relationships among the variables of interest. 


\section{Results}

\section{Classroom attendance}

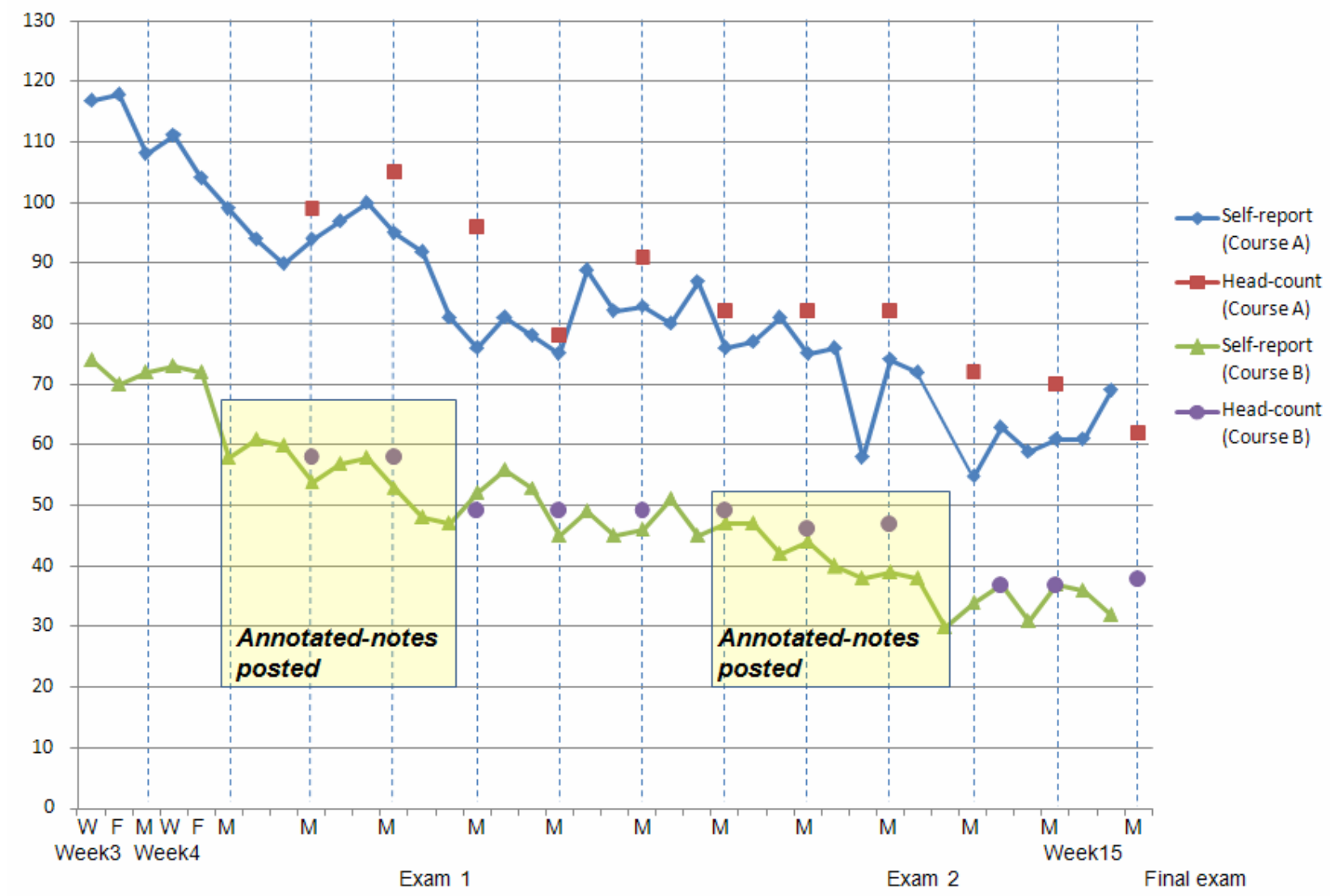

Figure 1. Frequency of classroom attendance over time in Course A and B

Figure 1 illustrates the number of students attending class throughout the semester in both courses. The figure shows a gradual decrease in classroom attendance in both courses as the semester progressed. Attendance at the start of the semester for Course A was 80\% (117 of 147) and decreased to $48 \%$ (69 of 144) by the end of the semester. Similarly, in Course B the attendance rate at the start of the semester was 85\% (74 of 87) which dropped to $45 \%$ (31 of 71) by the end of the semester. Although the instructor of Course B uploaded the annotated-notes immediately after each lecture only in week $5,6,7,11,12$, and 13 , no major changes in attendance rate were found during this period. An interesting finding, again as seen in Figure 1, is that the actual head count in both courses is consistently higher than the student self-report. This suggests that students tended to underreport their class attendance.

Students' perception of classroom attendance, note-taking behavior, and learning Table 2 displays the mean and standard deviation for items in the survey. The purpose of presenting this data is not to compare the results of the two courses, but rather to better understand the impact of posting notes given differences in classroom note posting strategies. Recall that in Course A, the instructor posted annotated notes immediately after each class. In Course B, the instructor alternated his strategy of posting notes using two conditions. In the first 
condition the instructor did not post the annotated notes until several days prior to assessment. In the second condition the instructor posted annotated notes after class.

Table 2. Results of students' perception on classroom attendance, note-taking behavior, and learning

\begin{tabular}{|c|c|c|c|c|c|}
\hline \multirow[t]{2}{*}{ Questions } & \multirow[t]{2}{*}{ Scales } & \multicolumn{2}{|c|}{$\begin{array}{c}\text { Course A } \\
(n=46)\end{array}$} & \multicolumn{2}{|c|}{$\begin{array}{c}\text { Course B } \\
(n=40)\end{array}$} \\
\hline & & Mean & SD & Mean & SD \\
\hline \multicolumn{6}{|l|}{ Perception of classroom attendance } \\
\hline I learn better when I attend classes. & \multirow{2}{*}{$\begin{array}{l}\text { 1. Strongly disagree } \\
\text { 2. Disagree } \\
\text { 3. Neutral } \\
\text { 4. Agree } \\
\text { 5. Strongly agree }\end{array}$} & 3.43 & 1.28 & 4.33 & 1.02 \\
\hline My presence in class is important. & & 3.04 & 1.40 & 4.03 & 1.07 \\
\hline How many times did you miss this class? & $\begin{array}{l}\text { 1. } 0 \\
\text { 2. } 1 \sim 2 \\
\text { 3. } 3 \sim 5 \\
\text { 4. } 6 \sim 10 \\
\text { 5. } 10 \sim \\
\text { 6. Missed most of the } \\
\text { times }\end{array}$ & \multicolumn{2}{|c|}{$\begin{array}{l}\text { 1. } 12.5 \% \\
\text { 2. } 20.0 \% \\
\text { 3. } 27.5 \% \\
\text { 4. } 20.0 \% \\
\text { 5. } 22.5 \% \\
\text { 6. } 12.5 \%\end{array}$} & \multicolumn{2}{|c|}{$\begin{array}{l}\text { 1. } 32.5 \% \\
\text { 2. } 5.0 \% \\
\text { 3. } 37.5 \% \\
\text { 4. } 15.0 \% \\
\text { 5. } 10.0 \% \\
\text { 6. }-\end{array}$} \\
\hline
\end{tabular}

\section{Perception of note-taking behavior}

In general, I print and bring handouts for class.

In general, I take notes during class.

1. Never
2. Sometimes
3. Always

\begin{tabular}{|l|l|l|l}
1.80 & .86 & 2.60 & .63 \\
\hline 1.85 & .76 & 2.80 & .46 \\
\hline
\end{tabular}

Perception of learning

I paid more attention to the lecture materials being presented when I had a print-out of the pre-class notes with me in class.

The material being presented during class was easier to understand when I was able to preview (or print) the pre-class notes. The way the instructor posted his notes helped my learning.

\begin{tabular}{|c|c|c|c|c|}
\hline \multirow{3}{*}{$\begin{array}{l}\text { 1. Strongly disagree } \\
\text { 2. Disagree } \\
\text { 3. Neutral } \\
\text { 4. Agree } \\
\text { 5. Strongly agree }\end{array}$} & 3.13 & .91 & 4.13 & 1.04 \\
\hline & 3.43 & .91 & 3.58 & .93 \\
\hline & 4.09 & .82 & 4.15 & .92 \\
\hline
\end{tabular}

How much impact does posting notes have on your ...

\begin{tabular}{l|l|c|c|c|c} 
note-taking behavior? & 1. Not at all & 3.09 & 1.05 & 2.18 & 1.15 \\
\hline classroom attendance? & 2. Less likely & 2.59 & 1.11 & 1.51 & .88 \\
\hline 3. Somewhat likely & 4. Very much & 2.33 & 1.03 & 1.58 & 1.01 \\
\cline { 5 - 6 }
\end{tabular}

In Course A, student perception of the statement "I learn better when I attend classes" leaned only slightly toward agreement as indicated by the mean score of 3.43. This slight positive level of agreement is repeated on the item "My presence in class is important" as indicated by the 
mean of 3.04. When asked about the number of times students missed class, $55 \%$ of students reported missing more than 6 classes in the semester.

In order to gather additional information about students' perception of the importance of class attendance, students were asked to respond to the item, "Please specify the reason for why you think your presence in class is important or not." Twelve students indicated 'posted notes' as a contributing factor to not attending class, as exemplified by one student's remark regarding the instructor of Course A, "[H]e has great notes that are basically self explanatory." This comment suggests that perhaps students may be lulled into a false sense of security that the posted notes will be sufficient to help them learn. This notion is supported by the following student comments:

- "There isn't anything that we do in class that isn't available on the website after class.

- "Anything that we do in class is then put directly online and it's all neatly color coded and organized. It just makes not going to class extremely easy without any real drawbacks."

These comments suggest that students are not aware of potential drawbacks of solely depending on notes and not attending class. However, comments from other students suggest that they are aware of this issue. For example, one student said that "hearing the information makes me remember it later when using it for assignments or exams."

Regarding the perception of note taking behavior, the mean score for printing and bringing handouts to class is 1.8, approaching 'sometimes' on the scale. The mean score for taking notes during class was 1.85, also approaching 'sometimes' on the scale. Looking more closely, a total of 16 students responded that they never took notes in the course. When these students were asked to elaborate on their behavior related to note-taking for this class, most of the students who responded indicated the availability of instructor notes as the reason. For example, one student reflected, "The instructor provides $100 \%$ of the notes, so I take no notes. I try to follow them on the overhead when I am there..." This student comment is consistent with Instructor A's philosophy - providing detailed notes so students can devote their entire attention to the lecture. A total of 19 students responded that they sometimes take notes. One of those reported that, "I generally take very good notes but for this class I only occasionally added a few points to the handouts." A side issue, but nevertheless important is printing cost. One student, who selfreported 'never' printing and bringing the pre-notes to class, indicated that he did not have a printer here and had exhausted his free print quota. Printing of notes then needs to be a faculty consideration as students take many classes and may expend their print quota fairly early in the semester.

Students' perception of learning was measured by three Likert-type items using a scale of 1 to 5 , and several open-ended follow-up questions. Related to the question "I paid more attention to the lecture materials being presented when I had a print-out of the pre-class notes with me in class," the mean score was 3.13, indicating that most students had a neutral perception on this question. Regarding the question "The material being presented during class was easier to understand when I was able to preview (or print) the pre-class notes," the mean was 3.43 indicating that the most students tended to slightly agree with the statement. This last finding may be impacted by 
fact that many students reported not printing and bringing the notes with them to class. Regarding the question "The way the instructor posted notes helped my learning," the mean was 4.09. Note-posting strategies of this instructor may explain the number (35\%) of students who reported not taking notes during class. These students may have been relying heavily on the posted notes for their learning. Regarding the impact of posting notes, students reported that note posting strategies impacted their note-taking behavior, classroom attendance, and attention during lecture in that order. The mean scores for these are 3.09, 2.59, and 2.33 respectively.

Positive feedback from students who responded that they paid more attention in class when they had class notes available, revealed several themes. Specifically, "opportunities to write important notes in the print-outs," "clarity of Tablet PC presentation on the screen," and being able to "look ahead" in the notes were common reasons related to perceived increase in attention. Negative feedback from students who answered that they paid less attention in class when they had notes can be seen in following quotes:

- "I paid less attention because I already had the notes and had read over them."

- "I tended to just read the printouts rather than pay attention to lecture."

In Course B, where the partial pre-notes were to be printed and brought to class, the mean score for the question "I learn better when I attend classes," was 4.33, indicating a high propensity toward strongly agreeing with the statement. Regarding the statement "My presence in class is important the mean score is 4.03 , indicating students lean toward strongly agreeing with the item. Further supporting these data, 32.5\% of students surveyed never missed class. Overall, $75 \%$ of students reported missing less than 6 classes. Some of the elaborated comments on why students perceived their attendance in class to be important included the following:

- "Because I understand better when I see the professor solving a problem and explaining it."

- "Attending class helps put the information from the book in a clearer manner which is easier to understand. If I did not attend class, I would not trust myself to study the material nearly enough."

- "When you attend class you develop a better feel for what the instructor [thinks] are the most important concepts of the course, and the nature of how you will be expected to apply those concepts."

Regarding perception of note-taking behavior, the mean scores of the statement "In general, I print and bring handouts for class" and "In general, I take notes during class" were 2.6 and 2.8 respectively, both approaching 'always' on the scale. More specifically, 33 out of 40 responded that they always take notes. Some of their comments on their behavior related to note-taking for this class included the following:

- "I try to write everything down exactly as annotated."

- "I generally follow along with the writing on the tablet PC as it is written. Occasionally I will add a personal note in addition to what Professor adds so that I can emphasize important details that I know will be helpful later on." 
Regarding students' perception of learning, the mean score for the statement "I paid more attention to the lecture materials being presented when I had a print-out of the pre-class notes with me in class" was 4.13 , being slightly higher than 'agree' level. The response to the item "The way the instructor posted his notes helped my learning" was also quite high with a mean score of 4.15. Regarding the impact of posting notes, the mean scores for the impact on their note-taking behavior, classroom attendance, and attention during lecture were 2.18, 1.51, and 1.58 respectively, approaching 'less likely' on the scale. More specifically, one of the repeated reasons of no or less impact is because they take notes, pay attention to, and attend classes regardless of the availability of instructor's notes. Some of the students mentioned the following:

- "I try to take the best notes I can without having to rely on what is posted later."

- "[The instructor's] notes aren't a substitute for being in class."

- "I always went, regardless of the note-posting."

- "I still pay attention so I don't have to learn it on my own."

- "I take notes as if he won't post the information online as often as possible."

\section{Relationships among variables}

Correlational results from Course A show two significant correlations $(p<0.05)$. There is a significant positive correlation between classroom attendance and homework achievement and a significant positive correlation between homework achievement and exam achievement. Although causation cannot be determined, this finding indicates that the students who attend class more often tend to receive higher scores on their homework assignments. Students who get better results on homework also tend to get better results on exams.

Correlational results from Course B show several significant correlations $(p<0.01)$. Similar to Course A, there is a significant positive correlation between classroom attendance and homework achievement and a significant positive correlation between homework achievement and exam achievement.

Table 3. Correlational results of Course A

\begin{tabular}{lcc|c}
\hline \multicolumn{1}{c}{ Variables } & 1 & 2 & 3 \\
\hline $\begin{array}{l}\text { 1. Classroom } \\
\text { attendance }\end{array}$ & 1 & & \\
$\begin{array}{l}\text { 2. Achievement: } \\
\text { Homework }\end{array}$ & $.400^{* *}$ & 1 & \\
$\begin{array}{l}\text { 3. Achievement: } \\
\text { Exam }\end{array}$ & .213 & $.380^{* *}$ & 1 \\
\hline
\end{tabular}

Table 4. Correlational results of Course B

\begin{tabular}{l}
\multicolumn{1}{c}{ Variables } \\
$\begin{array}{l}\text { 1. Classroom } \\
\text { attendance }\end{array}$ \\
$\begin{array}{l}\text { 2. Achievement: } \\
\text { Homework }\end{array}$ \\
$\begin{array}{l}\text { 3. Achievement: } \\
\text { Exam }\end{array}$ \\
$\begin{array}{l}\text { * Correlation is significant at the } 0.05 \text { level (2-tailed) } \\
\text { * Correlation is significant at the } 0.01 \text { level (2-tailed) }\end{array}$
\end{tabular}




\section{Discussion}

The data appears to indicate that in each case, the slope of decline and fluctuation in attendance patterns are quite similar. Therefore for these two classes, posting or not posting post class notes does not seem to be a factor influencing attendance. No noticeable changes in attendance were found in Course B where the annotated post-class notes were posted under alternating time conditions. Rather, similar to Course A, students' attendance decreased gradually throughout the semester and did not fluctuate based on the note-posting strategy.

Interestingly, the instructor for Course B commented that he perceived a drop in attendance when he started to post annotated post class notes. However, it was not until the fourth week of classes that post-class notes became available to students. Attendance had already begun to decline. Was the instructor noticing an attendance pattern that perhaps would occur anyway? Perhaps the attendance pattern is consistent with what would happen in other similarly sized engineering classrooms? We feel this is a matter that warrants further investigation and have intentions of conducting research to investigate this more deeply.

While the posting of annotated post class notes did not appear to influence student attendance, the type of pre-class notes made available to the students did impact student regarding the importance of class attendance. In Course A where detailed pre-class notes were available; students did not place great importance on class attendance. In Course B, when partial notes were made available; students placed a higher value on class attendance. Additionally, student feedback indicated that students learned better by following in-class problem solving procedures. However, student perceptions did not seem to correspond with the behavior relating to actual student attendance, as the numbers continued to decline over the semester.

The practice of supplying complete detailed pre-class notes needs to be examined more closely. Students in Course A, who were supplied with detailed pre-class notes, were of the opinion that it was not important to take notes during class. Students in Course A also valued having the instructor's annotated notes. Students in Course B, who had partial notes, were of the opinion that it was important to take notes in class and that having the complete annotated instructor notes was unimportant. Are students' perceptions on the importance of taking notes influenced by access to the pre-class notes? Alternatively, the instructor notes may have other characteristics that potentially have impacted their perception on this issue. The current investigation reveals only that students place more value in class attendance and personal notetaking if provided with partial notes rather than the complete notes. Additional research needs to be conducted to better understand this relationship. 
Student perceptions regarding the importance of annotated notes is complex. Some see annotated notes as a boon to studying, self-checking, and as an important learning aid; others see annotated notes as a reason to not come to class. From a practical standpoint, the current investigation may suggest that only partial notes be made available to students prior to class and annotated notes withheld until after a class session. However, specific research should be conducted to test this hypothesis. Perhaps students need to be instructed on how to use instructors' pre- class notes as well as annotated-notes. Only further research can tell. Additional studies should be conducted that investigate and address questions such as: Who benefits from annotated notes? How are annotated useful in supporting and enhancing student learning? Do students who compare instructor notes to their own notes learn better? Is it the low achieving student who considers the instructors' notes as a substitute for being in class; or do instructors' notes help low-achievers fill in their incomplete notes, as claimed by Kiewra [3]? Additional research is necessary to answer these questions on the implications of posting annotated notes.

\section{Bibliography}

1. R. Toto., K.Y. Lim, and J. Wise, Supporting Innovation: The Diffusion and Adoption of Tablet PCs in The College of Engineering, in The Impact of Tablet PCs and Pen-based Technology on Education, 2007, D.A. Berque, J.C. Prey, and R.H. Reed, Editors. 2007, Purdue University Press.

2. R. Toto, M. Wharton, J. Cimbala, J. Wise. One Step Beyond: Lecturing with a Tablet PC. Computers in Education Journal, 2007. XVII(No. 3 July-September): p. 2-11.

3. Kiewra, K.A., Providing the Instructor's Notes: An Effective Addition to Student Notetaking. Educational Psychologist, 1985. 20(No 1): p. 33-39.

4. Grabe, M. and K. Christopherson, Optional student use of online lecture resources: resource preferences, performance and lecture attendance. Journal of Computer Assisted Learning, 2007. OnlineEarly Articles.

5. Knight, L.J. and S.J. McKelvie, Effects of attendance, note-taking, and review on memory for a lecture: encoding vs. external storage functions of notes. Canadian journal of behavioural science, 1986. 18(1): p. 52-61.

6. Barnett, J.E., Do Instructor-Provided Online Notes Facilitate Student Learning? The Journal of Interactive Online Learning, 2003. 2(2): p. 1-7.

7. Bonner, J.M. and W.G. Holliday, How college science students engage in note-taking strategies. Journal of Research in Science Teaching, 2006. 43(8): p. 786 - 818. 